\title{
RECOPILACIÓN DEL CONOCIMIENTO ORAL DE LA LENGUA Y CULTURA GARÍFUNA
}

\author{
María Dolores Álvarez Arzate \\ alvarez.arzate@yahoo.com \\ Universidad NaCional AutónOMA DE NiCARAgUA-MANagua \\ Bayardo Gámez Montenegro \\ bayardogamez@yahoo.com.mx \\ CENTRO DE INVESTIGACIÓN Y COMUNICACIÓN SOCIAL, SinsLANi
}

\begin{abstract}
RESUMEN
El presente estudio trata de las tradiciones que configuran la identidad cultural de los garífunas/garinagu asentados actualmente en el territorio nicaragüense y tiene como finalidad apoyar a la revitalización de su lengua y cultura.

Se confirma la existencia de portadoras y portadores activos que contribuyen a la recopilación del conocimiento oral con quienes se abordan temas como: alimentación, vida cotidiana, juegos infantiles, organización social, relaciones de parentesco, economía, educación, fiestas y rituales, instrumentos musicales, manifestaciones artísticas, medicina tradicional, migraciones y vivienda.
\end{abstract}

Palabras clave: Garífunas, lengua, cultura, tradiciones. 


\begin{abstract}
The present study deals with the traditions that shape the cultural identity of the Gariphuna/Garinagu currently settled in Nicaraguan territory and are intended to support the revitalization of their language and culture.

It confirms the existence of active bearers that contribute to the collection of oral knowledge who covers topics like: diet, daily life, playgrounds, social organization, kinship, economy, education, festivals and rituals, musical instruments, artistic, traditional medicine, migration and housing.
\end{abstract}

Key words: Gariphuna, language, culture, traditions. 


\section{INTRODUCCIÓN}

La Unesco ha emprendido acciones para contribuir a la recopilación del conocimiento oral de la lengua y cultura garífuna. En el caso de Nicaragua se realiza una investigación de campo en 2007 y en 2009 con el interés de actualizar los datos y complementar con nuevos hallazgos lo que hasta ahora se ha documentado. Esta investigación contó con fondos de la propia Unesco para llevarla a cabo.

El estudio tuvo como objetivo general realizar un acercamiento al estado del arte sobre las expresiones culturales del patrimonio intangible garífuna y sobre el conocimiento de las/los portadores, que permita en un futuro contribuir a la recuperación de la cultura garífuna en Nicaragua.

Como objetivos particulares se presenta un directorio de expertos propios que portan, conservan y hablan la lengua y expresiones culturales del pueblo garífuna; sistematiza las formas metodológicas y procedimientos reportados para la salvaguarda y trasmisión oral de sus conocimientos y prácticas; caracteriza las tradicionales utilizadas por los portadores para la salvaguarda y trasmisión de los conocimientos orales sobre la lengua y expresiones culturales del pueblo garífuna; y presenta las referencias bibliográficas consultadas y otras identificadas durante la investigación. 


\section{METODOLOGÍA}

La metodología utilizada fue del tipo investigación social cualitativa sobre la base del paradigma de Grounded Theory, dado a conocer por Glaser y Strauss en 1967, que plantea un proceder flexible, franqueza en la determinación de los conceptos previos, baja incidencia de las/los investigadores en el contexto y con los sujetos investigados, análisis inductivo basado en datos empíricos, construcción de categorías e hipótesis de trabajo y validación de los resultados con expertas/expertos.

La metódica se organizó en cuatro momentos, el primero dedicado a la búsqueda de literatura de referencia y elaboración del diseño metodológico; le siguió el trabajo de campo en diciembre de 2007; después, el procesamiento y análisis de los datos. Para finalizar con un cuarto momento en abril de 2009 durante el cual se hizo la validación del informe con portadoras y portadores, expertas y expertos, en 2009.

Los ejes temáticos para la recolección de datos fueron: 1. creación de un directorio de expertos propios y portadores de las expresiones culturales garífunas; 2. sistematización de las formas metodológicas y procedimientos compartidos por los portadores para la salvaguarda y trasmisión de sus prácticas, y 3. caracterización de las tradicionales utilizadas por los portadores para la salvaguarda y trasmisión de los conocimientos orales sobre la lengua y expresiones culturales del pueblo garífuna.

La sección de resultados en el informe sigue la lógica del estudio de casos (Stake 1995), dado que se dio seguimiento al conocimiento oral de la lengua y cultura garífuna, considerando cada concepto como un microcaso único para luego armonizar el todo.

Las técnicas de campo empleadas fueron la búsqueda de informantes mediante la «bola de nieve» (Ander 1978), que consiste en localizar individuos típicos que a su vez conducen a otros hasta saturar la muestra teórica y agotar la selección de casos. Con ellos se utilizó la técnica de entrevistas centradas en el tema (Witzel 2000) realizadas en un ambiente cotidiano en el seno de las comunidades.

Para el criterio de selección de la muestra teórica (Glaser y Strauss 1967), se entrevistó a personas que reunieran al menos uno de los siguientes criterios: autoidentificarse como garífuna, hablar lengua garífuna, vivir de manera estable en la zona, tener liderazgo y reconocimiento social. En total se entrevistó a 44 personas, de ellas 3 
viven en Bluefields, 22 en Orinoco, 4 en Justo Point, 3 en San Vicente, 5 en La Fe. También se entrevistó a 7 expertas y expertos no garífunas.

La técnica de observación directa (Malinowski 1922) se aplicó durante los recorridos en las comunidades de Orinoco, San Vicente, La Fe y en la ciudad de Bluefields.

La técnica de la observación participante (Geertz 1973) se aplicó en el proceso de «vivir cultura» en un ambiente cotidiano, compartiendo las actividades de las/los actores sociales tales como preparar alimentos, correr bajo la lluvia, asistir a eventos sociales, actividades de pesca, tertulias en el caño, curas espirituales, danza y música.

El análisis de los datos (Barton y Lazarsfeld 1984) se hizo con base en la deconstrucción profunda de los datos singulares con el fin de encontrar sus relaciones internas y externas. Posteriormente se llevó a cabo la reconstrucción de los modelos y tipos que predominaron y con ello se llegó a la formulación de los constructos integradores o ejes temáticos. 


\section{CONTEXTO}

Las comunidades garífunas de Nicaragua se encuentran localizadas en la cuenca de Laguna de Perlas, calculada por el Instituto Nicaragüense de Estudios Territoriales (INETER) en $532.41 \mathrm{~km}^{2}$, a una distancia de 45 kilómetros al norte de la ciudad de Bluefields. Orinoco, la comunidad principal, se localiza en $12^{\circ} 33^{\prime} \mathrm{LN}$ y $83^{\circ} 42^{\prime} \mathrm{LO}$.

Imagen1. Mapa de Orinoco, Laguna de Perlas

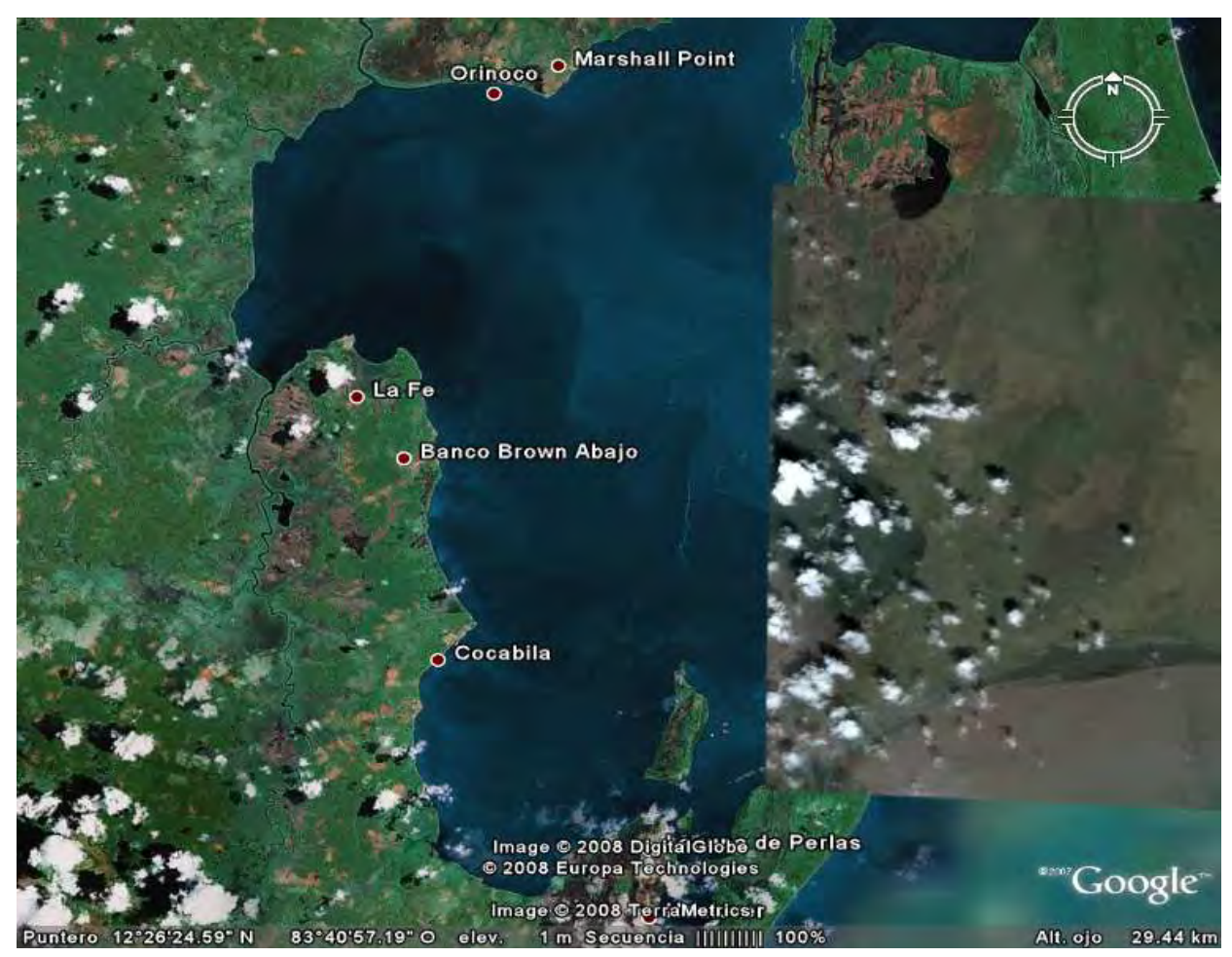

Fuente: Tomado de Google Earth: http://earth.google.es

La trayectoria de localización territorial garífuna en Centroamérica se ha construido con base en los datos publicados por autores como Ramón Rivas (2000), Nancy González (1997), Carlos Alemán (2005), William Davinson (1080), Jaime Wheelock (1999), y los citados por Dolores Figueroa (1999): Pim (1863), Boyle (1868), Collinson (1870).

En síntesis, su origen se remonta al continente africano, desde donde fueron trasladados por los franceses — católicos- hacia la isla de San Vicente y desterrados por ingleses — protestantes—, a partir de 1797, a la isla de Roatán en Honduras. Luego se 
dispersaron hacia Belice, Guatemala, Nicaragua y Costa Rica. Las primeras comunidades en Nicaragua fueron Lauba, San Vicente y Justo Point. En 1912 el garífuna Joseph Sambola fundó la comunidad de Orinoco. Su población se estima en 2,000 personas con base en el Segundo Informe sobre Desarrollo Humano en Centroamérica y Panamá (2003).

Las comunidades garífunas son Orinoco, San Vicente, La Fe, Brown Bank, Wawashang y Justo Point. Otras comunidades vecinas son de población miskito como Marshall Point, Kakabila, Awas; y de población creol y mestiza como Laguna de Perlas, Hallover y Kukra.

La comunidad de Orinoco tiene cinco barrios: Down Town, Up Town (Hill Town), Spanish Town, Brasil, y Paraíso. En las poblaciones San Vicente, La Fe, Brown Bank, Wawashang y Justo Point, no hay barrios.

El marco jurídico que protege directa e indirectamente a la población de Nicaragua se encuentra en la Constitución Política, publicada en el Diario Oficial La Gaceta No. 68 de 8 de abril de 2005 (1987/2005) en sus Arts. 5, 89, 90 y 91. Ley No.162 o Ley de Uso Oficial de las Lenguas de las Comunidades de la Costa Atlántica de Nicaragua, publicada en La Gaceta, Diario Oficial, No. 132 de 15 de julio de 1996. Ley No. 28 o Estatuto de Autonomía de las Regiones de la Costa Atlántica de Nicaragua, publicada en La Gaceta, Diario Oficial, No. 238 de 30 de octubre de 1987. Ley No. 445 o Ley del Régimen de Propiedad Comunal de los Pueblos Indígenas y Comunidades Étnicas de las Regiones Autónomas de la Costa Atlántica de Nicaragua y de los Ríos Bocay, Coco, Indio y Maíz, publicada en La Gaceta Diario Oficial, No. 16 de 23 de enero de 2003. Ley No. 217 General del Medio Ambiente y Los Recursos Naturales. Publicada en La Gaceta No. 105 de 6 de junio de 1996. Declaración del Día Nacional Garífuna el 19 de noviembre en Nicaragua, Decreto No. 37-2006, aprobado el 15 de junio de 2006.

En el ámbito internacional se encuentra la Convención sobre la Protección y Promoción de la Diversidad de las Expresiones Culturales signada en la $33^{\text {a }}$ Conferencia General de Unesco (París, 3 a 21 de octubre de 2005). Sin embargo, en la agenda jurídica de Nicaragua se encuentra pendiente la decisión del Estado sobre la suscripción del Convenio 169 de la Organización Internacional del Trabajo. 
TRADICIONES QUE CONFIGURAN LA IDENTIDAD CULTURAL GARÍFUNA

\section{EN NICARAGUA}

Las formas metodológicas y procedimientos tradicionales para la salvaguarda y trasmisión de sus prácticas y conocimientos sobre la lengua y expresiones culturales del pueblo garífuna han sido identificados a partir de ejes temáticos/constructos integradores que se exponen a lo largo de este capítulo.

Una primera observación acerca de la exposición de los resultados es hacer saber a las/los lectores que las personas entrevistadas son portadoras y portadores de la cultura garífuna en las comunidades, y eso explica la delimitación de un antes situado en las prácticas de sus padres, es decir, de las familias fundacionales; un antes situado en las memorias de sus experiencias personales vividas y un ahora vital y cotidiano.

Un ahora el cual se utiliza como contraste entre el hoy y las nociones de nostalgia de un ayer silenciado por el aislamiento geográfico e invisibilización social e institucional que deriva en una vida aislada a lo largo de varias décadas (1912-1980), durante las cuales no tuvieron suficientes contactos significativos con otras comunidades de la cuenca de Laguna de Perlas, del resto del territorio nacional y de las comunidades garífunas de varias zonas de la costa Caribe de Centroamérica. 


\section{ALIMENTACIÓN}

La base de la alimentación se concentra en la captura de peces: sábalo real, machaca, curuma, bagre, sábalo, chacalines, tiburón y corvina; mariscos: camarones, ostiones y almejas; animales silvestres: cerdo warry; cultivos de musáceas: banano; fabáceas: frijol; oleaginosas: maíz y coco; euforbiáceas: yuca y mandioca, y tubérculos como papa y quiquisque.

En noviembre es el mes de los chacalines, [nuestros padres] agarraban, vendían y regalaban a todo el mundo. La captura se realiza con anzuelo, redes, atarrayas o trasmallo (Clarisa Crisanto, diciembre 2007).

Las tradiciones de captura de alimentos en la laguna y en el bosque se realizan siguiendo un conjunto ritual que enlaza familia, cantos y socialización. Largas horas de espera para la captura permiten una vida colectiva bastante activa y cercana.

Éramos tan pobres que, para pescar, poníamos pescado y bastimentos como carnada y cocinábamos solo en agua, leche de coco y asado, que también llamamos barbecue (Raquel Álvarez, diciembre 2007).

Los platillos tradicionales que forman parte del paladar garífuna son el puré de plátanos $f u$ $f u$, la tortilla de yuca bamí o ereba, el dugitu o guiso de papas, el gallo pinto con aceite de coco y el Johny Cake, pastelillo que se consume en velorios.

Los bastimentos más usados son yuca, malanga, quiquisque, banano, plátano cuadrado, fruta de pan, arroz, maíz, frijol, pungapi; se acompañan con fuentes de proteína como las carnes de venado, chancho warry, pescados, chacalín, cangrejo, camarón, tortuga, cusuco, guilla, almeja, jaiba, pollo, gallina y huevos de gallina. Algunas frutas son apetecidas como la piña caribe, naranja, toronjas y banano. La bebida refrescante es el grefity - cususa de caña o de arroz.

En las fiestas se come sopa de pescado y panes dulces. Se prepara una bebida de jengibre con arroz en la pascua y quien lo hace regala en la comunidad. Las personas que iban a trabajar llevaban 
casabe, pescado seco y coco para las jornadas en el bosque [nuestros padres]. La preparación permitía que estos alimentos se conservaran en buen estado por largo tiempo, especialmente el casabe (Augusto López, diciembre 2007).

Imagen 2. Mariscos para la alimentación

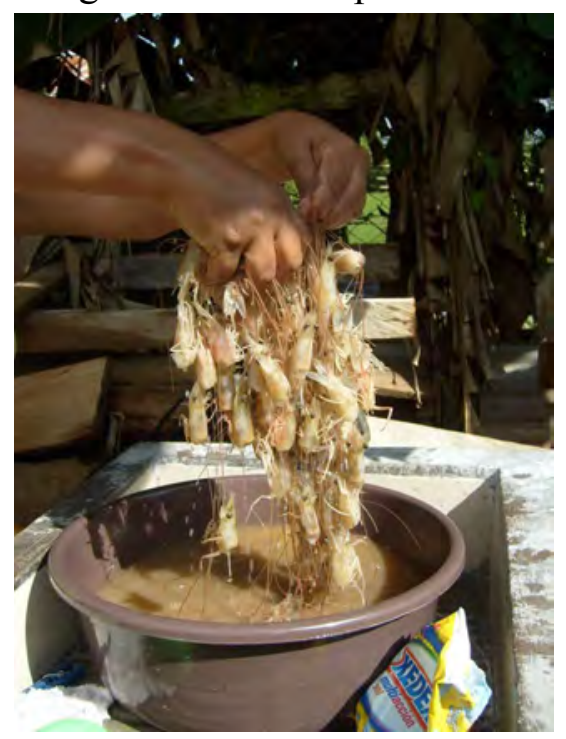

Fotografía de B. Gámez.

\section{La entrevista con Marcelina Zenón ilustra con sus recuerdos las tradiciones, costumbres y tecnologías utilizadas para la preparación y conservación de alimentos preservadas en la cultura garífuna, la cual se expone a continuación:}

[Nuestros padres] utilizaban el pino para prender el fuego y el candil para alumbrar por las noches. Se usaba bastante harina para cocinar y de los sacos de la harina se hacían los vestidos, éramos muy pobres a veces un solo teníamos un vestido y andábamos descalzos. Cazaban warry, venado, cusuco y guilla. El que cazaba repartía la carne entre la familia, se salaba la carne, se ahumaba y una parte se guardaba. Las carnes se podían hacer asadas o cocidas en agua con leche de coco. Para conservar el pescado se salaba se le atravesaba un palito y se ponía a ahumar o a secar al sol. Usaban para cocinar unas porras con patitas para sostenerse. Los primeros platos eran de madera planos y hondos. Tomábamos en jícara y comíamos con jícara [posiblemente segmentada en gajos a manera de cuchara]. El pescado dejaba un olor fuerte en las jícaras. Los primeros platos los trajeron de Puerto Cabezas [Bilwi], eran gruesos y también trajeron vasos de vidrio. Desde Costa Rica trajeron otros objetos como el plato hondo de peltre. Ahora todo esto ha sido sustituido por plásticos. Asaban el 
pescado metiéndoles unos palitos y lo comíamos con rondón. También, para asar el pescado lo cortaban de la cabeza para abajo, luego le hacían rayas diagonales en su piel, le echaban sal y lo ponían al sol. Ahora la gente le pone limón y sal y lo echan a freír o lo guardan en la refrigeradora. La fuente de energía para cocinar era la leña. Muchas veces comían los alimentos directamente de las porras con las manos, esto daba un importante sentido de comunidad porque participaban todos tomando de la misma olla. La abuela y los niños comían primero y hasta que se llenaban, entonces empezaban a comer los adultos. Algunos adultos comían afuera de la casa porque no había suficientes bancas. Para comer y socializar se hicieron bancas de madera amarradas con bejucos y una tabla para poner las cosas. En la casa había un lugar especial para guardar el agua de tomar, el agua era fresca y de buen sabor. Los pozos eran buenos, se les ponía una tapa para que ninguno cayera por accidente. Como bebida se usaba el ginger, licor hecho de caña de azúcar llamado cususa. Antes se hervía el jugo de caña y le llamaban ginger, con ese jugo llenaban sus jícaras y se ponían alegres. Esta nueva generación no lo sabe. Chicha de yuca, licor de banano maduro, licor de arroz, licor de chicha de maíz. Beber no era asunto de domingos, se bebía todo el tiempo. Se cocinaba en ollas de hierro y se tapaban con hojas de plátano. Para la cocción se tapaba las porras con hojas de plátano. En el mismo instrumento donde pilaban [descascaraban] el arroz, hacían la machuca con todos los bastimentos, hacían como un puré y lo comían con caldo de pescado. Se sembraba y se cosechaba el arroz, se pilaba y se cocinaba en [agua de] coco. Se cocinaba casabe, plátano, yabs o yam, cus cus, yuca, quiquisque, banano, ñame, hay de tres colores, blanco, amarillo, lila (Marcelina Zenón, diciembre 2007).

En la actualidad, los momentos para ingerir los alimentos están relacionados con los espacios de socialización familiar, son tiempos durante los cuales se comparte en grupos sentados en bancas de madera lis, alrededor de una mesa simple o bien en comunidad en los corredores de sus viviendas de madera. Son tiempos en los que se conjugan conversaciones amenas, anecdotarios y otras actividades asociadas como curaciones y acicalamiento. 


\section{VIDA COTIDIANA EN EL PERIODO FUNDACIONAL}

En el periodo fundacional (1912), la vida cotidiana era sencilla y apacible, se disfrutaba con facilidad y no había contactos externos que irrumpieran en el acontecer de las comunidades garífunas. La adversidad del clima lluvioso, frecuentes tormentas y huracanes, condiciones pantanosas de los suelos y las distancias, propició que las relaciones de las familias garífunas de Laguna de Perlas se viesen distanciadas con respecto a las familias garífunas que continuaron su recorrido en busca de lugares idóneos para asentarse más hacia el norte: Honduras, Guatemala y Belice. Presentamos tres testimonios garífunas que reflejan cómo eran aquellos tiempos:

Antes se tenía mayor colaboración entre todos. Siempre se ha tenido una unión y ayuda mutua en la comunidad. Había una distribución de los trabajos como limpiar la casa. No se tenía televisión, solo radio. Se tenía el culto matutino en la casa, ahora se va olvidando esta práctica. Antes se tenía un respeto a los mayores, cualquier miembro de la comunidad podía hacerle una observación o castigo. El cuido de los ancianos es responsabilidad de todos (Clarisa Casildo, diciembre 2007).

Antiguamente [cuando nuestros padres] se construían bancos de madera amarrados con bejucos. Las abuelas y abuelos fumaban tabaco en pipas, comían tabaco y escupían jugo de tabaco (Pedro Pablo Molina, diciembre 2007).

[En el tiempo de nuestros padres]... Comían tabaco americano, se vendía el de hojas grandes. Fumaban en pipas, hombres y mujeres. Eran tan fuertes que con frecuencia dormían. Los dientes se ponían café con el tabaco. Las pipas se hacían con dos trozos de madera cuidadosamente elegida, una servía de base para el tabaco y otra de pipa propiamente por donde se aspiraba el humo del tacaco. Se usaba para la pipa una ramita muy fina, a veces se usaba una rama de chile ... [Cuando éramos niñas] Usábamos ropa hecha de tela de sacos de harina. Con los sacos de la harina se hacía ropa, unos vestidos llamados sambucos. Se utilizaban telas de mantas que cubrían desde el cuello hasta los tobillos, tenían un par de mantas, no usaban calzados, eran muy pobres y en algunos casos usaban botas. Los vestidos tenían una bolsa secreta para guardar dinero. Cada mujer hacía su ropa a mano y los hilos los tomaban de la misma tela [generalmente obtenida de los sacos de harina de trigo]. Las mujeres usaban vestido largo, tenía un corte redondo arriba con un corte recto enfrente que se cerraba con dos botones a la derecha en la ropa de mujer, le ponían dos bolsas cuadradas a la altura de la cadera y a la derecha una bolsa oculta en forma de mano. Las mangas eran parte de la misma pieza 
sin hacer cortes. El largo llegaba a los talones. El vestido quedaba tan amplio como la tela y se amarraba en la cintura con un cordel de la misma tela. La ropa interior era llamada bagge, se hacía de la misma tela, era un pantaloncito largo que se amarraban con un cordel de tela y dos botones al lado izquierdo de la cintura. Jocosamente le llamaban jesperáte! o witting. El domingo se usaba un gorrito cerrado que se amarraba con dos cordones de la misma tela. El domingo usaban vestidos con varias blondas o vuelos y se ponían un pañuelo que se ajustaba con un cordel y un botón. No usaban zapatos. Cuando usaban eran cerrados y todos eran el mismo modelo, hombres y mujeres. Pero no todos usaban zapatos. Para salir de la Laguna, las mujeres llevaban bolsos grandes donde ponían vestidos y zapatos para el viaje. Para embellecer usaban polvera con mota de algodón. Usaban perfumes para ir a misa, los que compraban en las ciudades (Marcelina Zenón, diciembre 2007).

Esta vida cotidiana es reflejo de la nostalgia por el periodo fundacional fuertemente modificado debido al contexto contemporáneo que deviene de los movimientos migratorios y la influencia de las prácticas del consumo y la globalización.

\section{JUEGOS INFANTILES}

Los juegos forman parte de la tradición oral para educar a las/los garífunas. A través de observaciones directas en las comunidades se pudo recopilar una larga lista de juegos, que podrá ampliarse con la participación de las y los portadores de las tradiciones. Los juegos presenciados son: bañar en el río y jugar en los cultivos, canicas o chibolas, naipes, chalupa, dominó, básquetbol, fútbol, béisbol, hándbol, softbol, juegos de casitas de muñecas y pesca recreativa de cangrejo y pescado con anzuelo. 
Imagen 3. Niñas jugando en Orinoco

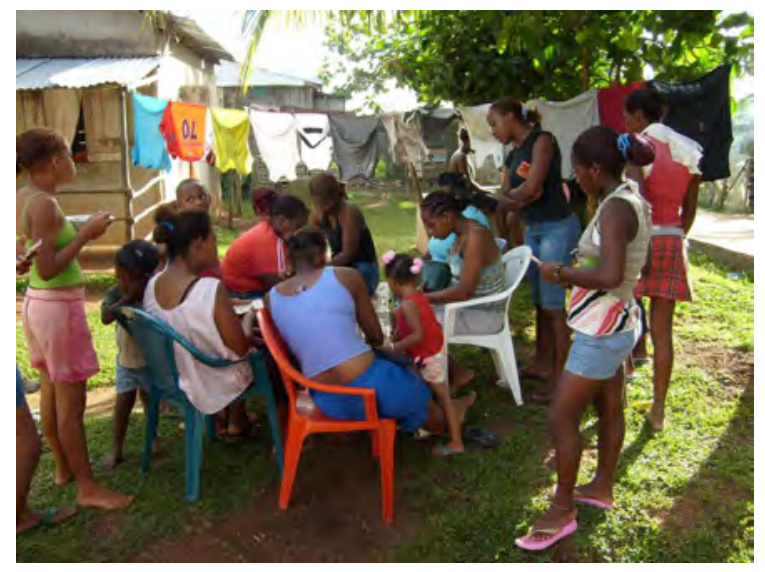

Fotografía de B. Gámez.

La vida amorosa tiene expresiones de complicidades jocosas frente a las estrictas normas comunitarias, de way one; se trataba de poner aceite en las ventanas para que los novios pudieran escapar si los descubrían. «En los tiempos de siembra o de cosecha, van tantas personas que los adultos no se fijan en los detalles y allí es donde se enamoran». «Durante las jornadas de trabajo en el bosque se salía en familias y en grupos grandes de familias, y allí en medio de la vegetación se juntaban las parejas» (Marcelina Zenón, diciembre 2007).

Imagen 4. Niños jugando en Orinoco

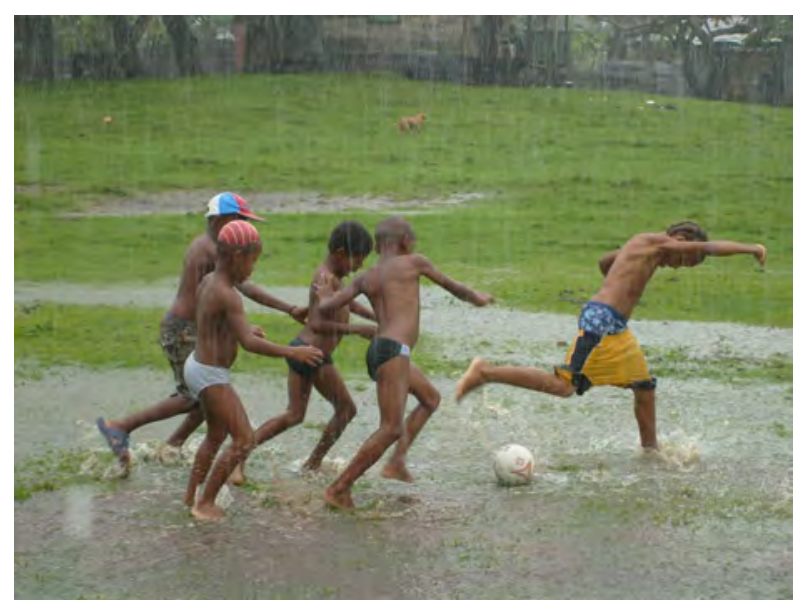

Fotografía de M. Álvarez. 
Cuando buscaban una novia se les solicitaba a los padres el permiso, jalar hasta cierto tiempo y casarse. Se hacen regalos de las dos familias como ropa, perfumes, vestido y pantalón (Augusto López, diciembre 2007).

La socialización se sigue realizando en tres espacios principales: el hogar, el momento del lavado de la ropa y aseo personal en los caños de agua dulce, y en la búsqueda de alimentos en la laguna, el bosque o en algunos claros del llano circundante.

\section{ORGANIZACIÓN SOCIAL Y RELACIONES DE PARENTESCO}

Las formas de llamar a las personas se dictan por su edad, y con mucho énfasis hacia las mujeres, a quienes llaman Miss, Anti (aunt), Mam (abuela). Otra forma es mediante apodos, los cuales normalmente están fonéticamente muy alejados de sus nombres formales y no necesariamente indican expresiones en garífuna - v. gr. Miss Masa, Miss Kuna.

Es una característica entre garífunas el tipo de apellidos que se toman del español y francés, lo que hace una gran diferencia con los creol, quienes utilizan apellidos de origen anglosajón.

Las familias garífunas están siempre emparentadas entre los Estrada, Sambola, Álvarez, González, López, Estrada, Zenón, Arana, Jiménez, Portillo. Los afro descendientes que son Álvarez son garífunas. Venían de Honduras (Marcelina Zenón, diciembre 2007).

Existió un control riguroso de las líneas de descendencia principal que se identifican por grupos o clanes, mismas que se han ido perdiendo. Por ejemplo,

La familia Zenón viene de Honduras y se asientan en Justo Point (Absalón Velásquez, diciembre 2007).

Las familias son grandes y están emparentadas entre sí. Estrada, Sambola (Marcelina Zenón, diciembre 2007).

Actualmente a los jóvenes ya no les interesa saber sobre sus parientes, no siguen el control que llevaban los ancianos (Kensy Sambola, diciembre 2007). 
Las relaciones de parentesco están entrecruzadas por varias razones: en primera instancia por la población poco numerosa, la localización en lugares aislados entre sí y aislados de las ciudades de mayor importancia. En segundo lugar debido a que las personas son longevas, de prole numerosa y de edad temprana para la procreación. Esta combinación de factores permitió que los padres continuasen procreando hijos y que sus hijos mayores, en el mismo lapso de tiempo, a su vez ya tuvieran otros hijos. En la socialización convivieron hijos y nietos sin distinción alguna, y al momento de la formación de nuevas parejas y su respectiva procreación se ha dado como resultado que la vinculación entre los padres de los nuevos hijos sea de padre y tío al mismo tiempo. Es decir, presenta una fuerte y marcada endogamia que se suma a factores subjetivos como: 1. la discriminación y mutuo rechazo entre creol y garífuna, y miskito y garífuna; y 2. la marcada inclinación a la vida confesional católica de los garífuna que les alejaba de la influencia morava y anglicana asumida por los creol y miskito. Cabe mencionar que las opciones confesionales son: católica, anglicana, pentecostés y adventista.

Imagen 5. Familia en San Vicente

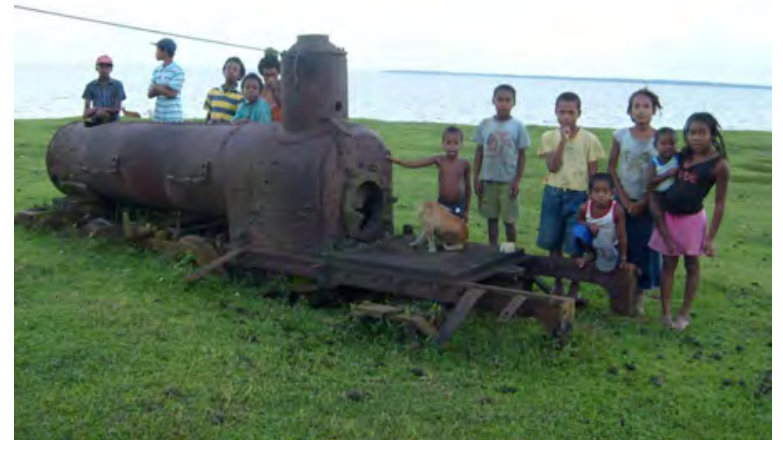

Fotografía de B. Gámez.

El concepto de cónyuge es diferente para hombre y para mujer. En el hombre se da con la mujer con quien reside de manera estable y no necesariamente lo obliga a la monogamia. De hecho, es parte de su dinámica el tener relaciones poligínicas simultáneas incluso con 
procreación. En cambio, en las mujeres el hecho cierto es que tienen hijos y no interesa demasiado de quién puesto que «son los hijos». Actualmente, lo que les interesa es tener una relación armoniosa y de provisión. En el caso de existir violencia, no dudan en negarse a continuar la vida conyugal y asumen, eventualmente, una nueva relación.

\section{ECONOMÍA}

La vida económica es resultado de la conjugación de varios factores, entre ellos el clima, las estaciones del año, los periodos de apareamiento y reproducción de las especies acuáticas y terrestres, la vocación de los suelos, el manejo del agua y la relación con las costas, los humedales y el bosque tropical.

\footnotetext{
Los garífunas viven de la pesca y de la agricultura. No hay ninguna empresa que ofrezca trabajo a la gente, por eso es que vamos a buscar el monte. En tiempos pasados había bastante chacalín y pescado, y cuando se acababa la temporada podíamos volver al monte, pero ahora no porque otras gentes han venido cortando árboles para poner ganado. Los pescados se los llevan los acopiadores y no queda ninguno en la comunidad (Augusto López, diciembre 2007).
}

Imagen 6: Niñas y niños en el muelle de Orinoco

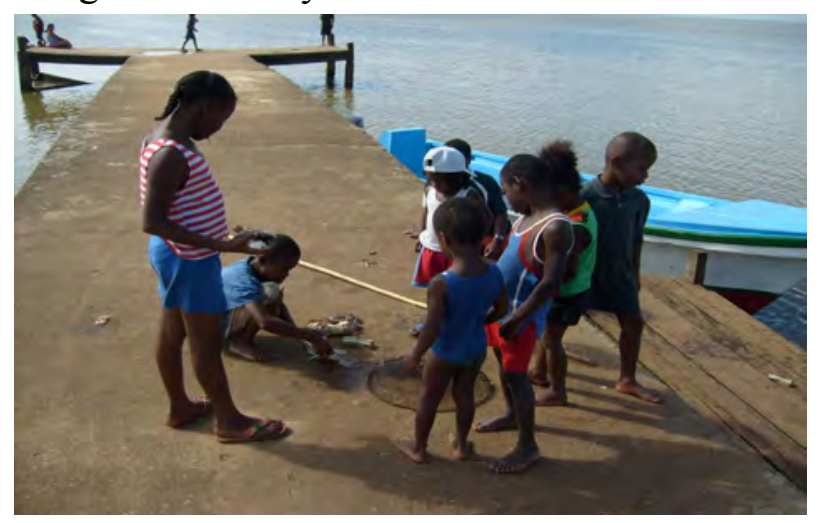

Fotografía de B. Gámez. 
Entre los garífunas se hace una minuciosa observación sobre los cambios climáticos y la dirección de los vientos del norte y del este, de ello se derivan las decisiones sobre la producción; por ejemplo en la pesca, que se inicia en enero y va hasta mayo o junio, así como en las formas particulares de realizar la actividad agrícola. De esta manera lo recuerdan ancianas y ancianos:

Para obtener recursos adicionales se iban en cayuco hecho de caoba de nibuna para El Bluff y allí vendían sus productos y el cayuco, con eso ya tenían para comprar otros productos como hachas, harina, nailon, anzuelos. Cuando un cazador llegaba con un warry, primero lo repartía y luego dejaba una parte para salarlo y ahumarlo para guardar (Raquel Álvarez, diciembre 2007).

[Antiguamente] Hacían cayucos, pasaban varios meses para hacerlos, usaban caoba y cedro, estos botes los vendían en Bluefields y ahí compraban otros productos como la harina, el hacha y otros. Las redes se hacían de nailon, se medían por brazos y la pesca se realizaba de forma colectiva, pescando con anzuelo, en los meses de mayo y junio; los meses mejores de la pesca eran en febrero, marzo y abril ... La gente de Laguna viajaba por el mar hacia Puerto Cabezas y a Bluefields en velero. La fecha del viaje se fijaba con el [estado] del tiempo. El viaje de ida y vuelta tardaba ocho días. Antiguamente se tenían cayucos y vela. Se hacían de cedro macho, palo de agua. Lo hacían los hombres, se pasaban hasta ocho días seguidos labrándolo, después se arrastraban para pasarlo al agua, la vela se hacía de manta y actualmente se hace de plástico. Los botes son diferentes, para el mar y para la laguna. Ahora que hay motores, se adapta la cola del cayuco para colocar el motor y le llamamos panga, hoy son de fibra de vidrio. La panga es que se corta la cola y se coloca la corta y se coloca el motor. Para el futuro ya no habrá cayuco porque ya no hay árboles para hacerlos, ahora solo hay potreros de españoles. Se tienen dos tipos de botes, uno solo para el río y otro para la laguna, se hace con machete, son el cayuco o dori ... Actualmente se vive de la pesca y de la agricultura. Antes se tenía gran cantidad de chacalines y pescado, no se tenía necesidad de buscar el monte. Se ha cultivado plátano, malanga, yuca, maíz y frijol, pero ya no se tienen tierras para cultivar el frijol. [Ahora] Existe una invasión de los mestizos sobre la tierra de los garífunas. Antes se cazaba venado, warry y tepescuintle, ahora se están extinguiendo, solo existen en ciertos lugares (Augusto López, diciembre 2007).

En la actualidad, el trasporte se hace por bote de vela y panga de motor. El alto costo del combustible hace que la población garífuna utilice gran parte de sus recursos monetarios para el pago de trasporte, lo cual debilita su economía de subsistencia. 
La relación de las y los garífunas con el territorio tiene ahora más importancia debido al avance de la frontera agrícola y la falta de un reconocimiento institucional a sus territorios, lo cual afecta la vida jurídica y productiva de la población.

Cada quien tiene su carril y su mojón para identificar la propiedad. Y cada dueño tiene que limpiar sus carriles. Se tienen tierras comunales, se ponen los linderos pero no se tienen los documentos. Aquí se ve la importancia de los carriles, unos los tiene limpios y en las esquinas cada quien pone sus mojones para sus miembros. La tierra es propiedad comunal, nosotros no tenemos títulos de propiedad individual (Augusto López, diciembre 2007).

Existe una gran riqueza de instrumentos de trabajo y formas de producción, cada una relacionada con el tipo de producto que se desea obtener, ya sea de la pesca, la cacería, la agricultura o el cuidado de animales.

Imagen 7: Artefactos culinarios

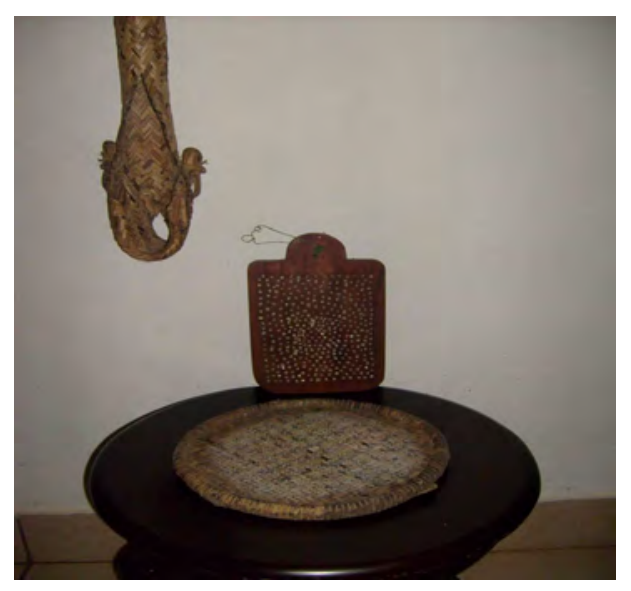

Fotografía de B. Gámez.

En la pesca se identifican: cayuco, lancha, atarraya, anzuelo, redes, machete, remos, trasmallo, canalete. Para la agricultura existe la macana, azadón, machete y hacha.

Algunas prácticas cotidianas se han visto modificadas con la llegada de la energía eléctrica; para unos es un avance, para otros un hecho que les invade y contamina. 
Antes de la llegada de la luz eléctrica utilizaban el pino para hacer luz, luego cuando llegó el kerosene se usaban las botellas de vidrio y se les ponía tela para alumbrar (Raquel Álvarez, diciembre 2007).

La llegada de la energía eléctrica generó cambio en los hábitos: almacenamiento de alimentos, la comunicación por antenas y la utilización de los equipos de sonido (Kensy Sambola, diciembre 2007).

La vida económica recibe un fuerte impulso procedente de las remesas familiares que envían los que trabajan en el extranjero, esto permite una vida de subsistencia mediante la pesca y la agricultura.

\section{EDUCACIÓN}

En Orinoco existen tres niveles educativos: el preescolar, la escuela de primaria Enmanuel Mongalo, y el Instituto de secundaria. Para alcanzar el nivel universitario las/los jóvenes deben trasladarse a la ciudad más cercana, Bluefields, en donde tendrán que socializar con personas de los otros pueblos: miskito, creol, mestizos costeños y mestizos del Pacífico.

\footnotetext{
Actualmente se enseña la lengua en la escuela, pero la profesora Victorina no tiene el dominio del idioma, es un nivel bajo. Se tiene deserción por falta de motivación de los padres e indisciplina. Se tiene una inscripción de 115 alumnos y se han tenido diez promociones de bachilleres en la escuela secundaria Se puede aprender la lengua a partir de la lectura de cuentos. Actualmente se tienen leyendas en inglés. Las cartillas de enseñanza de los cuentos deben ser trilingües: garífuna, inglés y español. Es necesario tener libros de textos que se adapten a los valores culturales garífunas y realizar el intercambio de capacitarse en la lengua en Belice y en Honduras (Frank López, diciembre 2007).
}

Por inspección directa se pudo constatar que el sistema educativo cuenta con recursos predominantes en idioma español y las clases se imparten en ese idioma. El inglés creol se habla en la vida cotidiana y como socialización, y el garífuna es del ámbito de pocas personas ancianas. No se desea hablar español pero existe una realidad a la que es difícil sobreponerse, los libros de texto de la parte avanzada de primaria y de la secundaria se 
imprimen en español. Adicionalmente, algunos libros escolares son traídos de Honduras, en donde la lengua de contacto es el español, por tanto la forma escrita de la lengua se acerca a la pronunciación de este idioma, lo cual incluye una tensión con respecto a la lengua de contacto de los garífunas de Nicaragua, que es el inglés creol, lengua predominante entre los afrodescendientes de Laguna de Perlas y Bahía de Bluefields.

La lengua garífuna está segmentada en dos: por un lado, los portadores que lo hablan con los arcaísmos de la época en que lo usaron como lengua franca; por otro lado, niñas y niños que han aprendido canciones y cuentos con la maestra de Belice que les dio clases en 2007 en el nivel preescolar.

Sobre el tema del aprendizaje de la lengua garífuna existe una consideración muy importante: los garífunas de Honduras y Guatemala tienen contacto con el español y los de Belice con el inglés, esto tiene su valor al momento de decidir las personas que enseñarán garífuna en Orinoco y otras comunidades, ya que la lengua de contacto en esta zona es el inglés creol.

Solo existe registro de un recuerdo sobre la educación recibida hace más de cincuenta años, la cual es descrita por Marcelina Zenón en Orinoco: «En tiempo de Somoza vino una maestro, pero se fue. Los viejos pudieron estudiar cuando fueron a Costa Rica» (Marcelina Zenón, diciembre 2007).

Es importante reconocer que existen importantes esfuerzos de las comunidades garífunas de Honduras y Guatemala quienes han participado a lo largo de los treinta últimos años en revitalizar la lengua, no obstante es indispensable generar el reforzamiento del aprendizaje de la lengua garífuna en preescolar y su continuidad mediante la implementación de una hora de clase de lengua garífuna en la primaria completa.

Lo anterior conlleva la necesidad de elaborar cartillas de iniciación aprendizaje de la lengua garífuna que tengan en consideración las formas particulares del uso en las comunidades de Laguna de Perlas, y que tomen en cuenta elementos importantes como rasgos geográficos e identidad cultual, mediante una presentación amena y didáctica con ilustraciones sencillas y comprensibles que contribuyan a la asimilación de la lengua y fortalecimiento de los valores culturales. 


\section{FIESTAS Y RITUALES}

Existen tres tipos de fiestas, las religiosas confesionales, las tradicionales y las populares. En años recientes se han incluido algunas fiestas institucionalizadas como efemérides que responden a criterios del Estado, tales como fiestas patrias y días internacionales.

[En el tiempo de nuestros padres] Se hacían fiestas en las casas con instrumentos de maracas y tambores. Habían canciones de la gente de antes con guitarra, instrumentos de cuerda, se vivía bien, tranquilos, sin pleitos. Se hacían fiestas de fin de año y año nuevo llamadas maskarit. Las mujeres se vestían de unos pantalones grandes y máscaras de cartón. Se juntaban las comunidades e intercambiaban para hacer fiestas. Se hacían panes dulces y bebida de jengibre con arroz y se regalaba de una casa a otra para las fiestas de pascua ... La fiesta de maskarit se organizaba con hombres vestidos de mujer, usando cartones para hacer las máscaras (Augusto López, diciembre 2007).

Actualmente, se incluye en el calendario festivo el 19 de noviembre como Día Nacional Garífuna, instaurado en Nicaragua por el Decreto Presidencial 37-2006. 
Imagen 8. Grupos tradicionales

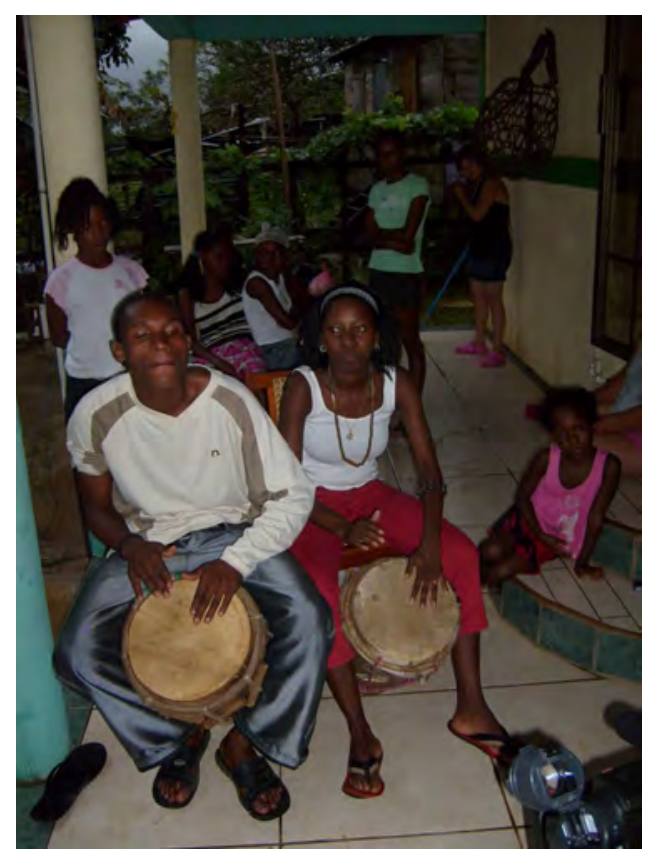

Fotografía de B. Gámez.

El ritual del dugu/chugu o wala gallo, es el ritual dedicado a los ancestros para la cura de una persona gravemente enferma; es conducido por el sukia previo a comunicaciones con los antepasados por medio de los sueños. Participa gran parte de la comunidad.

El ritual del chugu se hace para varias personas y se realizan ofrendas de agrado a los ancestros. Cuando las personas están enfermas se realiza el walagallo con los tambores, se prepara comida y se baila alrededor del enfermo. Pero ahora no queda bien porque han perdido el idioma garífuna. Pero si recupera el idioma puede recuperar esa clase de sistema para curar. Cuando una persona se enferma se hace una fiesta que se llama wallagallo y esa enferma se levanta. Actualmente se hace pero no se hace muy bien porque se ha perdido el idioma (Augusto López, diciembre 2007).

En la actualidad, las prácticas rituales han disminuido, unos argumentan que se debe a los costos de las celebraciones en tanto otros se refieren a la pérdida, sobre todo en los jóvenes, de las creencias en el poder y autoridad de los ancestros. 


\section{INSTRUMENTOS MUSICALES}

Las fiestas tienen como alma del proceso el tambor y el siseró. Un estudio minucioso de carácter etnomusicológico escrito por Idalberto Suco (1987) reconoce los siguientes garaones o tambores, fabricados a partir de un tronco de madera y cuero de venado tensado y amarrado con bejucos o sogas.

Los instrumentos son: Libiama garavon, significa tambor primero, mide $25.5 \mathrm{~cm}$ de diámetro y $39 \mathrm{~cm}$ de alto. Linigui garavon, significa corazón del tambor, tambor principal y segundo, mide $30 \mathrm{~cm}$ de diámetro y $45 \mathrm{~cm}$ de altura. Luruvan garavon, significa ayuda, tercer tambor, mide $27 \mathrm{~cm}$ de diámetro y $40 \mathrm{~cm}$ de alto. King drummer, tambor más grande y principal para ejecutar en los rituales. Sísiras o siseró, son sonajas fabricadas de jícaros y agarraderos de madera.

En la actualidad se siguen tocando los tambores, sin embargo las personas que participan declaran que hace falta la materia prima, ya que los animales y árboles del bosque han mermado y no disponen de suficiente material para reparar los que tienen ni hacer nuevos.

Imagen 9: Instrumentos musicales

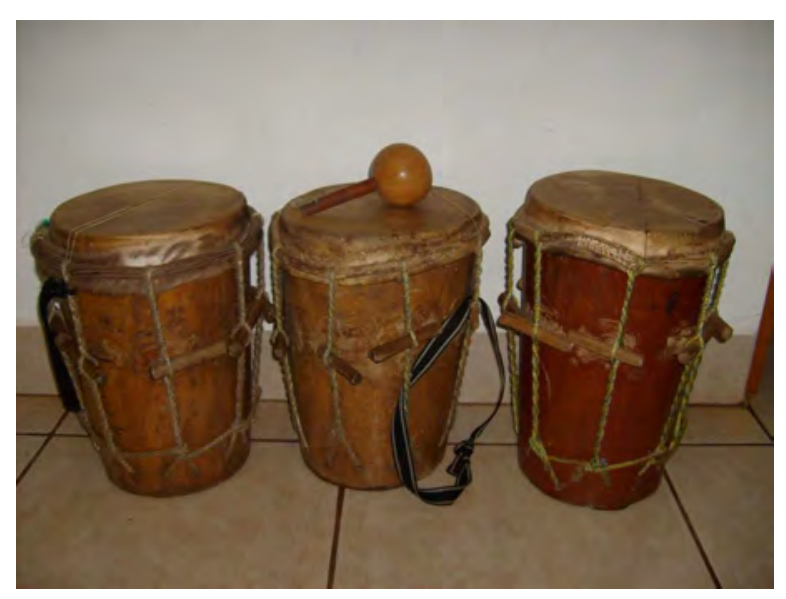

Fotografía de B. Gámez. 
Con frecuencia tocamos música con guitarras y con panas. No cantamos nada en especial a los niños. Cantábamos todo el tiempo. El canto incluyó palmear. Había canciones de acuerdo a las ocasiones (Marcelina Zenón, diciembre 2007).

La escasez de materias primas y la facilidad para obtener instrumentos industriales ha tenido como consecuencia la lenta sustitución de los instrumentos originales por instrumentos electrónicos que modifican sensiblemente los acordes de las piezas primarias, y en algunos casos tratan de imitar sones garífunas de otras zonas de Centroamérica, dejando a un lado la música autóctona.

\section{MANIFESTACIONES ARTÍSTICAS EN ORINOCO Y BLUEFIELDS}

En la actualidad son pocos los grupos organizados para la revitalización de las tradiciones artísticas, carecen de un sistema de educación musical y danzaria que les permita alcanzar mejor calidad.

Los grupos encontrados son: uno de cuatro jovencitas que realizan cantos tradicionales garífunas y danza a ritmo de punta; un dúo de jóvenes que tocan los tambores; un grupo infantil de danza, integrado por cinco niñas, se presentan cuando tienen visitas de delegaciones de turistas y en eventos especiales. Grupo de música y danza garífuna Spirit Dancers que se ubica en la ciudad de Bluefields y se ha presentado en la región y en el ámbito nacional. Un músico solista, Franklin Lowery, intérprete de música a ritmo de calipso y blues, con estilo caribeño. 
Imagen 10: Grupo de danza tradicional de niñas

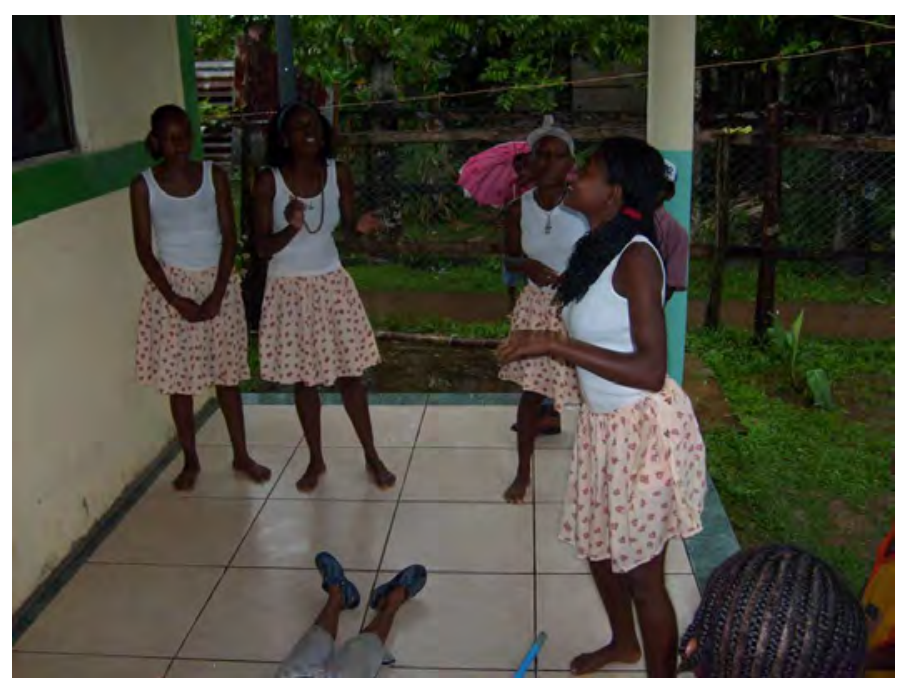

Fotografía de B. Gámez.

La riqueza de las manifestaciones culturales nos lleva a pensar en la importancia que tienen los espacios de comunicación social, radio y televisión, para emitir programas en lengua garífuna con apoyo del gobierno regional y las instituciones educativas del Estado y las universidades.

\section{MEDiCINA TRADICIONAL}

Actualmente entre los garífunas existe la creencia y práctica de curarse a partir de la medicina tradicional, esta se basa en la intervención de las y los curanderos, quienes utilizan yerbas, hojas de plantas, cáscara de ciertos árboles, algunas sustancias animales o minerales, acompañadas en algunos casos de oraciones. Existe el curandero que solo sana los piquetes de culebra, otros son especialistas en curas espirituales. En caso de enfermos muy graves solicitan la realización de un ritual, el Walla Gallo, aunque esto es menos frecuente.

Los testimonios de distintos especialistas, como los curadores de piquetes de culebra, parteras midwife y sacadores de muelas, son por sí mismos elocuentes: 
Simeón Zenón es el curandero de los piquetes de culebras, recibió las enseñanzas de su tío Aldrick Cayaso. Los enfermos entran un día a su casa y salen hasta el día siguiente. Las mujeres embarazadas y las que tienen menstruación no pueden entrar ahí. Al enfermo le da sed pero no puede tomar agua, solo café negro. No puede comer nada agrio ni dulce, solo guineo cocido sin sal. Se le daba cususa fuerte o ron mezclado con yerbas en nueve dosis. Simón Cash es el que cura las enfermedades espirituales. Para curar las enfermedades comunes se han utilizado algunas pastillas, calmantes del dolor y mezcla de algunas yerbas. Se han utilizado las pastillas mejoral, divina, matadolor, sulfatiasol con limón, para la diarrea cocimientos con guayaba. Para la calentura se usaba la vaselina para frotar el cuerpo en gruesas capas para hacerles sudar. Usan las botellas de agua florida americana para el dolor del corazón y los aires, las compran en Bluefields. Cuando la gente padece de anemia le dan cuculmeca con leche, algunos lo hacen para la venta, una señora prepara un litro que llamaba barril tónico y abre el apetito después de tomarse. Para la fiebre malaria les preparan una bebida amarga en vino Cóndor, con eso no padecen fiebre. Hace unos 20 años es que se tuvieron unos casos de jóvenes que miraban duendes, seres diabólicos, un hombre negro, que el duende era el dueño de un árbol grande en El Caño. Antes se tuvo un señor que estaba loco que tenían que amarrarlo y lo llevaban a Karawala para buscarle un curandero especialista. Antes no habían casos de epilepsia, actualmente se tiene uno en la comunidad de La Fe, uno en San Vicente y un joven en Marshall Point. Actualmente lo que se tiene son los casos de chavalos que arman bebedera y drogas y se descontrolan (Verónica Nancy Morales, diciembre 2007).

Tengo fe y corazón para ayudar a la gente, aquí me vienen a buscar desde lejos de diferentes comunidades. Estoy en disposición de enseñar a varios que tengan el interés y voluntad para aprender. Dios es el que me da bendiciones, todas las yerbas que uso son originales, son objetos del señor. Algunas yerbas se encuentran en el monte, otras tienen que buscar en el mercado de Bluefields o Monkey Point, se traen y se tienen guardadas para curar. Las culebras que existen en la zona son: el coral, la barba amarilla, wisni que es la culebra voladora, esta no es venenosa, y la tamagás que es la más venenosa, se come a sus hijos y abundan en los swampos, salen de noche a comer pescados y sapos, en el día duermen. Pero ellas atacan en cualquier tiempo y lugar. Se utiliza una semilla que se llama comida de culebra, es una semilla de color oscuro que tiene un grabado en forma de cruz, esta se restriega sobre la piel del enfermo para identificar donde está la picadura de culebra. En el caso de mujeres embarazadas o de personas con hernia se tiene que trabajar rápido para la curación. Al enfermo picado de culebra se le dan varias tomas de café amargo y tres tomas de ajo con aceite de robalo, después se le da un purgante de lexol. También he curado a perros, caballos, ganado, venado, gatos que ha sido picados de culebras. Tondaboll es la piedra de rayo, la piedra del cielo, sirve para curar, para liberar tensiones. Se coloca dentro de medio balde de agua, se tritura un ajo, se pone en un trapo y se echa al agua, se deja una hora en reposo, se hace la cruz en el pecho y después se baña 
con esa agua. Cansaya es la erisipela, esta se cura restregándose un sapo en las partes afectadas (Simón Zenón, diciembre 2007).

La gente se enfermaba de fiebre, catarro, malaria. Se utilizaban algunas yerbas y plantas para la curación como la raíz de cuculmeca para la sangre y el zacate limón para los resfríos (Marcelina Zenón, diciembre 2007).

El sacador de muelas era un personaje temido. Cuando tenía un dolor de muelas, fui a buscar al señor y me dijeron que no estaba, Entonces me fui a la playa con el gran dolor. Mi mamá me dijo llorando, vamos a la casa; no, yo voy a esperar al señor en la playa. Cuando por fin llegó el señor, me miró y dijo, hay que llevar a esta niña a Laguna [de Perlas], y cuando sacó sus tenazas para hacer algunos movimientos yo agarré al señor con las uñas y tenía que pelear del dolor. El señor dijo a mi mamá que nunca más llevara a sus hijos con él. Era tan temido que los niños corríamos lejos de él (Kensy Sambola, diciembre 2007).

\section{Dentro del sistema de prestigio se encuentra la partera o midwife, persona relevante a quien todas y todos deben el privilegio de haberles ayudado en el parto a las mujeres. Los testimonios revelan el cuidado y la delicadeza con que se trata el tema:}

Le atendía la midwife partera con la suegra, cortaban el cordón umbilical y lo amarraban con los cordeles que traían los sacos, le curaban el ombligo con alcohol y con sal, no se podían comer durante todo el embarazo el venado, tiburón, sábalo, y le daban plantas medicinales. Sobre la creencia de los niños embolsados [nacidos dentro de la placenta], lo que se hace es que al nacer separan al niño o niña de la placenta y colocan la placenta en una tela negra, la cosen y se regalaba para hacer medicinas. Ahora lo venden (Marcelina Zenón, diciembre 2007).

Los nacimientos eran atendidos por las parteras y los hombres quedaban afuera ... No se podía comer manta raya porque se pega en el fondo de la laguna y entonces el niño se pega al suelo y seca la placenta (Raquel Álvarez, diciembre 2007).

Para dar a luz estaban las parteras, antes habían bastante, ahora solo dos activas: Elma Hebber y Thelma Arana. Después del parto le daban un líquido amargo parecido a la quina, es una planta parecida al ayote, las hojas más finas, al cocer el agua le dejaban el monte. Actualmente usan romero, manzanilla y Agua Florida (Verónica Nancy Morales, diciembre 2007). 
Cuando un niño nacía lo atendía midwife, pero ahora lo atienden en conjunto en el Centro de Salud (Augusto López, diciembre 2007).

La medicina tradicional es una importante fuente de identidad cultural que se mantiene vigente en toda la comunidad garífuna de Centroamérica, lo cual se manifiesta en los viajes constantes de pacientes que buscan curación con distintos médicos tradicionales especializados y con prestigio en cada una de las comunidades.

\section{MigRACIONES}

Se reportan casos frecuentes de familias en diáspora actual debido a la búsqueda de mejores oportunidades, como la migración a Puerto Cabezas. Algunas frases refieren los motivos y los destinos:

[Ahora] La gente se va para Costa Rica, Gran Cayman, Estados Unidos, Panamá. Los motivos para reunirse son los encuentros familiares afuera de Orinoco. Los que están fuera no quieren volver (Marcelina Zenón, diciembre 2007).

\section{Imagen 11. Migraciones y nostalgia}

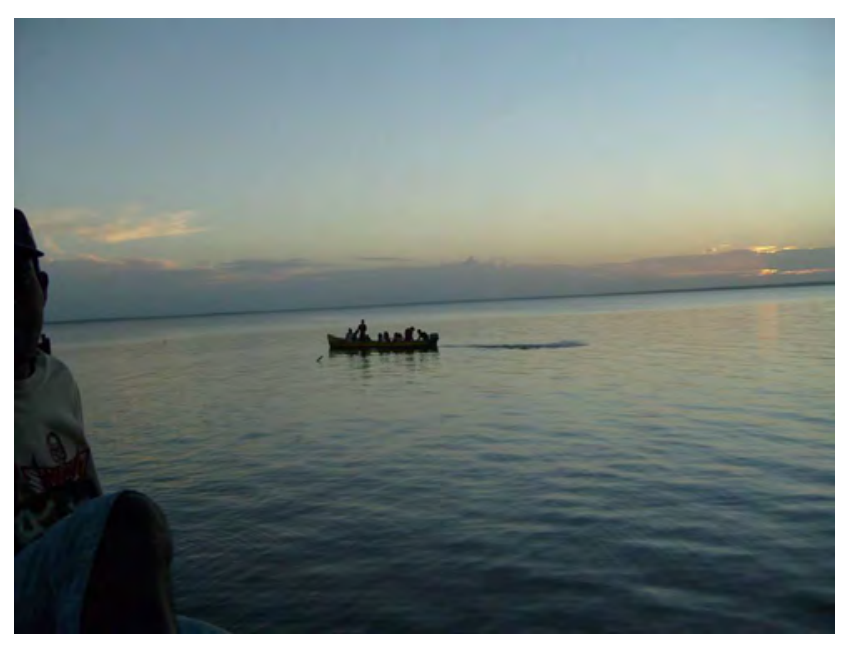

Fotografía de B. Gámez.

Las ancianas cuentan que sus hijos se han ido. Tuve trece hijos, cinco han muerto, los otros están afuera, Gran Cayman, Estados Unidos, Orinoco (Raquel Álvarez, diciembre 2007). 
Cuando terminábamos la primaria, nos mandaban a Bluefields a continuar los estudios y entonces el contacto viene siendo más creole. Una buena oportunidad de encontrarnos es el 19 de noviembre, Día Nacional Garífuna, vemos sobre todo a los viejitos. Cuando uno se va a estudiar a Bluefields te vas ligando a la cultura de los criollos. Cuando vas a estudiar pueden pasar años sin que regreses a Orinoco. Ves a los abuelos cuando vienen a la ciudad. Este año fui a Orinoco a la celebración del Día de los Garífunas el 19 de noviembre. Comemos baami, conversamos con los abuelos (Cindy Sambola, diciembre 2007).

En la actualidad hay poco interés por cultivar los vínculos afectivos y de historia y tradición oral. Las visitas son esporádicas y se han instrumentalizado a través de la relación con la remesa más que con las personas y su carácter de portadoras de la cultura.

\section{VIVIENDA}

Antes se hacían las casas mediante empalizadas o caña brava amarrada con bejucos, se embadurnaba de tierra por ambos lados de la pared hasta que se secara, techo de paja y suelo de tierra. Actualmente las casas están construidas en su base con zancos de madera para aislar de la humedad del ambiente, las paredes son de madera, presentan puertas y ventanas, techos de zinc. En otros casos la construcción es mixta de bloques de concreto, madera machimbrada - trabajada como tejidos- y techos de zinc. Los pobladores con más posibilidades económicas han construido sus viviendas a base de ladrillos de concreto y columnas de hierro y cemento, se ha presentado un cambio en el diseño arquitectónico por preservar más los materiales y estructura, así como para prevenir la humedad tropical y las consecuencias de los huracanes, debido también al alto costo de la madera.

Para realizar la construcción de las casas se iba al monte para cortar palos y hacer una empalizada, se cubría de hojas para evitar el paso del viento. La casa era con pared de madera y empalizada, se cubría con barro hasta cierta altura para separar los cuartos. La cocina era como un añadido, se preparaba el piso de tierra y agua, se apelmazaba. Actualmente se tiene que sacar un permiso para cortar un árbol (Augusto López, diciembre 2007). 


\section{Imagen 12. Viviendas tradicionales}

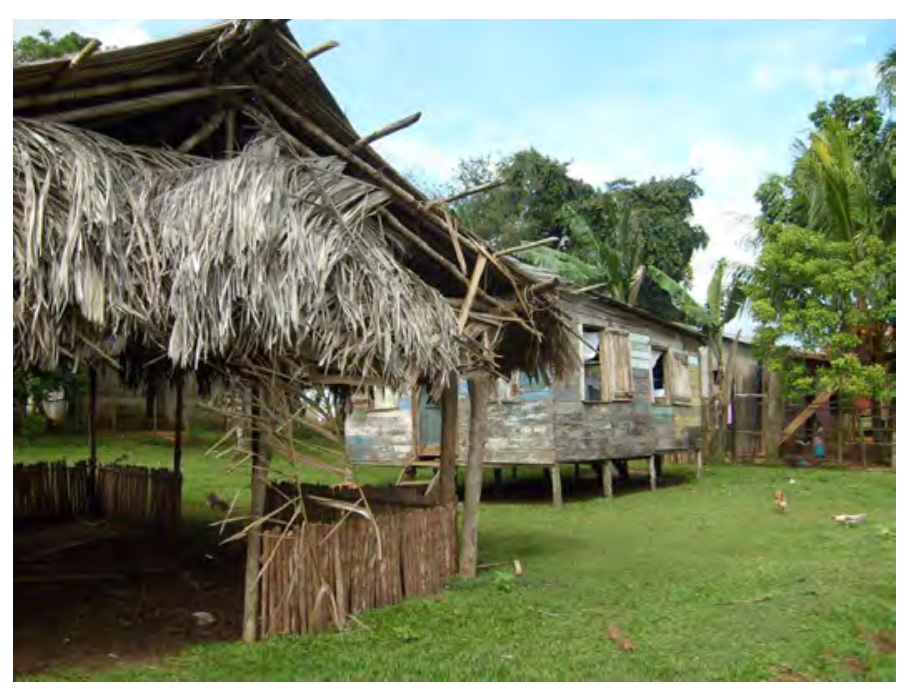

Fotografía de B. Gámez.

Las casas se hacían de palma, la fecha del corte depende de la luna, en el cuarto creciente. Esto es muy importante porque de lo contrario le da polilla. Usaban clavos galvanizados para fijar las piezas. Se hacían dos puertas, pocas veces tres, una en dirección al Este y otra al Oeste. La cocina se hacía afuera (Marcelina Zenón, diciembre 2007).

Por aquí han pasado los huracanes Fifi (1974) y Joan (1988), la gente se protegía muy bien y pasó un terremoto en San Vicente (Clarisa Casildo, diciembre 2007).

Las casas eran antes de madera y tablas. El techo con palma y bastante inclinado con postes de soporte. Al centro había puertas y ventanas a los lados. La cocina se puso a un lado de la casa como añadida. En la parte de afuera de la casa se hace una zanja alrededor para que no quede el agua en la casa. Hay que hacer una orilla grande y se sube tierra pegando como lodo hasta que se pone duro. Eso es para proteger del agua (Augusto López Sambola, diciembre 2007).

La frecuencia con que ocurren los huracanes y la disminución de la zona forestal hacen que la materia prima tradicional de madera sea sustituida por las construcciones de cemento. Esta realidad tiene ventajas frente a la destrucción de los huracanes, pero no es totalmente funcional ya que las casas de cemento suelen construirse a nivel del suelo, lo que no 
permite cubrir la funcionalidad y ventilación de las casas de madera construidas sobre pilares y zancos también de madera.

\section{CONCLUSIONES Y PERSPECTIVAS}

La revitalización de la lengua y cultura garífuna tiene tres grandes fortalezas: la vinculación constante con otras comunidades garífunas de Centroamérica, la existencia de portadoras y portadores activos, y el interés de instituciones como Unesco y diversas universidades por aportar a la recopilación del conocimiento oral generando bases de datos para posteriores trabajos de fortalecimiento de la cultura garífuna.

Algunas de estas responsabilidades son competencia de instituciones con quienes se pueden establecer alianzas, hermanamientos y diversas modalidades de cooperación para el desarrollo pleno de la comunidad garífuna de Nicaragua.

Se requiere de programas institucionales que aporten a la revitalización de la lengua y cultura garífuna, con énfasis en la capacitación de docentes, elaboración de materiales didácticos con base en la realidad nacional, incorporación de las canciones, cuentos, juegos y tradición oral en las cartillas escolares. Realizar acciones dirigidas a dar prestigio y visibilidad social a la cultura garífuna a través de asesoría, capacitación y divulgación con base en la profundización de investigaciones sobre las diferentes manifestaciones artísticas y culturales de la población garífuna. Contribuir con la difusión de los cuentos y leyendas tradicionales por medio de publicaciones periódicas, acompañados de ilustraciones elaboradas por niños y jóvenes de las comunidades garífunas.

Otras acciones pueden encaminarse hacia el fortalecimiento de los lazos entre el sistema de salud y la medicina tradicional, y muy especialmente el fortalecimiento del desarrollo y capacitación de las parteras.

En cuanto a su contexto y medio ambiente se necesita atender el reconocimiento y demarcación del territorio, la implementación de un Plan de Agua y Saneamiento Rural, la regulación de la pesca comercial que afecta la pesca tradicional, la regulación del uso y explotación de los ecosistemas y la biodiversidad, y el mejoramiento del incipiente y costoso sistema de trasporte y regulación de tarifas. 
En lo relacionado con las organizaciones y asociaciones del pueblo garífuna se necesita del fomento de las relaciones de intercambio para aprendizaje y uso fluido de la lengua garífuna en niñas, niños y jóvenes, con garífunas de Belice y Honduras, sin olvidar el acompañamiento al fortalecimiento y capacitación del liderazgo comunitario. 


\section{BIBLIOGRAFÍA}

Alemán, Carlos, 2005, «Auspicio y promoción de la lengua Garífuna». Documento.

Barton Allen y Lazarsfeld Paul, 1984, «Einige funktionen von Qualitativer Analyse in der sozialforschung». En Qualitative Sozialforschung, editado por C. Hopf y E. Weingarten. Stuttgart.

Cea D’Ancona María, 2001, Metodología cuantitativa. Síntesis, Madrid.

Davidson William, 1980, «The Garifuna of Pearl Lagoon: ethnohistory of an AfroAmerican enclave in Nicaragua». Ethnohistory 27, núm. 1.

Figueroa Romero Dolores, Víctor Obando, Isabel Estrada y Denisse Lapoutre, 1999, Orinoco, revitalización cultural del pueblo garifuna de la Costa Caribe nicaragüense. Ediciones Universidad de las Regiones Autónomas de la Costa Caribe Nicaragüense, URACCAN, Bluefields, Nicaragua.

Glaser Barney y Anselm Strauss, 1967, «Discovery of Substantive Theory: A Basic Strategy Underlying Qualitative Research». American Behavioral Scientist 8.

González Nancy, 1987, «Garifuna traditions in Historical Perspective». En Reading Belizean History. University of Maryland, Baltimore.

González Pérez, Miguel, 1997, Gobiernos pluri-étnicos: la constitución de las regiones Autónomas en Nicaragua. Universidad de las Regiones Autónomas de la Costa Caribe de Nicaragua, URACCAN, Plaza y Valdés, México. 
Obando, Víctor, Isabel Estrada, Dolores Figueroa y Denisse Lapoutre, 1999, Orinoco: Revitalización cultural de los pueblos garífuna de la Costa Caribe Nicaragüense. Ediciones URACCAN, Managua, Nicaragua.

Rivas, Ramón, 2000, Pueblos indigenas y garifuna de Honduras. Una caracterización. Editorial Guaymuras, Tegucigalpa, Honduras.

Stake, Robert, 1995, The Art of Case Study Research. SAGE, Thousand Oaks, California, United States.

Suco Campos, Idalberto, 1987, La música en el complejo cultural del Wala Gallo en Nicaragua. Casa de las Américas, La Habana, Cuba.

Valles Martínez Miguel, 1977, Técnicas cualitativas de investigación social. Reflexión metodológica y práctica profesional. Síntesis, Madrid.

Wheelock Román Jaime, 1981, La Mosquitia en la Revolución. Centro de Investigaciones y Estudios de la Reforma Agraria, CIERA, Managua.

Witzel Andreas, 1989, «Das problemzentrierte Interview». En Qualitative Forschung in der Psychologie. Grundfragen, Verfahrensweisen, Anwendungsfelder, editado por Gerd Jüttemann. Asanger, Heidelberg. 


\section{GLOSARIO}

Términos utilizados por las/los entrevistadas/os.

Baami: $\quad$ bastimento hecho a base de yuca seca y tostada en forma de círculo.

Bagee: $\quad$ ropa interior femenina.

Barbecue: asar carne.

Cansaya: erisipela.

Casabe: $\quad$ acepción del término baami, bastimento a base de yuca.

Chugu: $\quad$ ritual de invocación a los ancestros.

Cuculmeca: planta con propiedades medicinales.

Cusuco: mamífero silvestre comestible.

Cususa: $\quad$ bebida fermentada de maíz, caña de azúcar o de arroz.

Diguitu: guiso de papas.

Dori: $\quad$ embarcación de pesca artesanal.

Dubase: nombre de las antiguas casas.

Dugu: $\quad$ ritual de invocación a los ancestros.

Ereba: tortilla de harina de yuca.

Ginger: licor refrescante hecho a base de caña de azúcar. Los hay también hechos a base de frutas como piña, o yuca, banano, arroz y maíz.

Grefyty: $\quad$ cususa [licor] de caña o de arroz.

Guilla: mamífero silvestre comestible.

Jhony Cake: pastelillo de harina de trigo con saborizantes como jengibre y otras hierbas aromatizantes.

Machimbrada: madera trabajada como tejidos.

Mascarit: fiesta tradicional de fin de año y año nuevo.

Midwife: partera.

Nibuna: $\quad$ especie maderable apta para la construcción de embarcaciones.

Name: $\quad$ tubérculo.

Pungapi: bastimento.

Sambucos: vestidos hechos con telas de sacos de harina. 
Sukia: líder espiritual y curandero principal de la comunidad.

Swampos: pantanos.

Tepecuintle: mamífero silvestre comestible.

Titawé: raíces con propiedades medicinales.

Tondaboll: piedra rayo, meteorito. (Thunderball.)

Walagallo: ritmos que se danzan en los rituales del Dugu/Chugu.

Warry: cerdo silvestre.

Way one: situación en la que solamente hay una vía, de lo contrario representaría una catástrofe; se usa con picardía para hacer referencia a las hazañas por conquistar a la pareja en las relaciones de noviazgo.

Wismi: serpiente venenosa.

Witting: forma jocosa de llamar a la ropa interior femenina. 


\section{Anexo A. Portadoras y PORTAdores de la CUltura garífuna de Nicaragua}

En Bluefields:

Marcelina Zenón, Miss Maza, anciana, reside en Punta Fría. Entrevista 15.12.2007.

Pedro Pablo Molina López, pescador, reside en Punta Fría. Entrevista 15.12.2007.

Raquel Álvarez, Miss Kuna, anciana, reside en Beholden. Entrevista 15.12.2007.

En la comunidad de Orinoco:

Alejandro Estrada Sambola, curandero espiritual. Entrevista 17.12.2007.

Augusto López, productor agrícola. Entrevista 17.12.2007.

Bonifacio Colindres, anciano hablante de garífuna. Entrevista 07.04.2009.

Byron Goff, pulpero. Entrevista 18.12.2007.

Cindy Sambola, estudiante universitaria. Entrevista 16.12.2007.

Clarisa Crisanto, ama de casa. Entrevista 17.12.2007.

Devery García, pescador. Entrevista 07.04.2009.

Frank López, docente. Entrevista 16.12.2007 y 18.12.2007.

Frank Lowery, cantautor tradicional. Entrevista 07.04.2009.

Ivette Sambola, asalariada. Entrevista 19.12.2007.

Kensy Sambola, socióloga y antropóloga. Entrevista 16.12.2007.

Lucila Casildo, costurera, participante del ritual Wala Gallo. Entrevista 18.12.2007.

Ludrixk Estrada, curandero tradicional. Entrevista 07.04.2009.

Marciana Sambola, curandera. Entrevista 18.12.2007 y 07.04.2009.

Raymundo Mejía Álvarez, originario de Cosuna, Honduras. Entrevista 17.12.2007.

Simon Cash, curandero tradicional. Entrevista 07.04.2009.

Simón Zenón, curandero de picados de serpiente. Entrevista 18.12.2007.

Verónica Nancys Morales, enfermera en Centro de Salud. Entrevista 19.12.2007.

Victorina López, maestra de garífuna. Entrevista 07.04.2009.

Wiston Sambola, marinero, periódicamente embarcado en crucero (ship out).

Entrevista 16.12.2007 y 19.12.2007.

Yeison López, futbolista de la selección nacional. Entrevista 18.12.2007.

Yoni Flores, originario de Cosuna, Honduras. Entrevista 17.12.2007. 
En la comunidad de Justo Point:

John García, pescador. Entrevista 06.04.2009.

Edwin Blake, maestro. Entrevista 06.04.2009.

Eleanor Sambola, anciana. Entrevista 06.04.2009.

Rodrigo Estrada, agricultor. Entrevista 06.04.2009.

En la comunidad de San Vicente:

David Sambola, anciano. Entrevista 17.12.2007.

Felipe Wilson, poblador dedicado a la agricultura. Entrevista 17.12.2007.

Lola Sambola, líder natural y portadora de la línea de parentesco principal.

Entrevista 17.12.2007.

En La Fe:

Cornelio López Davis, pescador y cantautor. Entrevista 08.04.09.

Cornelio López Sambola, pescador y cantautor. Entrevista 08.04.2009.

Estela Jiménez, midwife-partera. Entrevista 08.04.2009.

Nicanor Morales, agricultor. Entrevista 08.04.2009.

Robert Sambola, pescador y cantautor. Entrevista 08.04.2009.

Expertas/os no-garífunas consultados:

Leonardo Cash, artesano de confección de botes. Entrevista 07.04.2009.

Margarita Antonio, comunicadora y antropóloga. Entrevista 22.04.2009.

Maricela Kauffman, curadora de arte. Entrevista realizada 14.04.2009.

Mario Miranda Guevara, médico en Centro de Salud. Entrevista 17.12.2007.

Neidy González, antropóloga. Entrevista 15.12.2007.

Paula Ingram, antropóloga. Entrevista 15.12.2007.

Víctor Obando, sociólogo, docente de URACCAN. Entrevista 15.12.2007. 
ANEXO B: FOTOGRAFÍAS SOBRE LA VIDA COTIDIANA TOMADAS EN ABRIL DE 2009

Imagen 13. Marciana Sambola preparando casabe

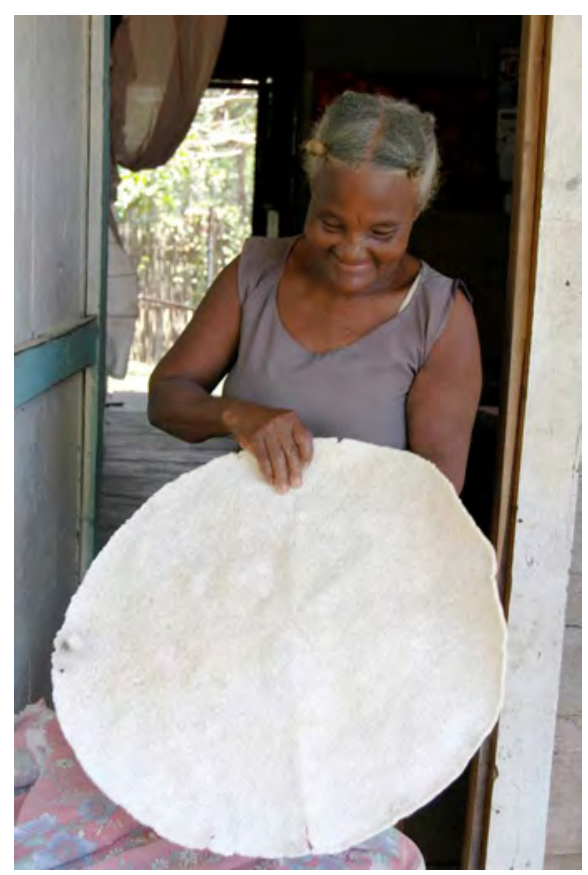

Fotografía de J. Molina.

Imagen 14. Victorina López y sus estudiantes

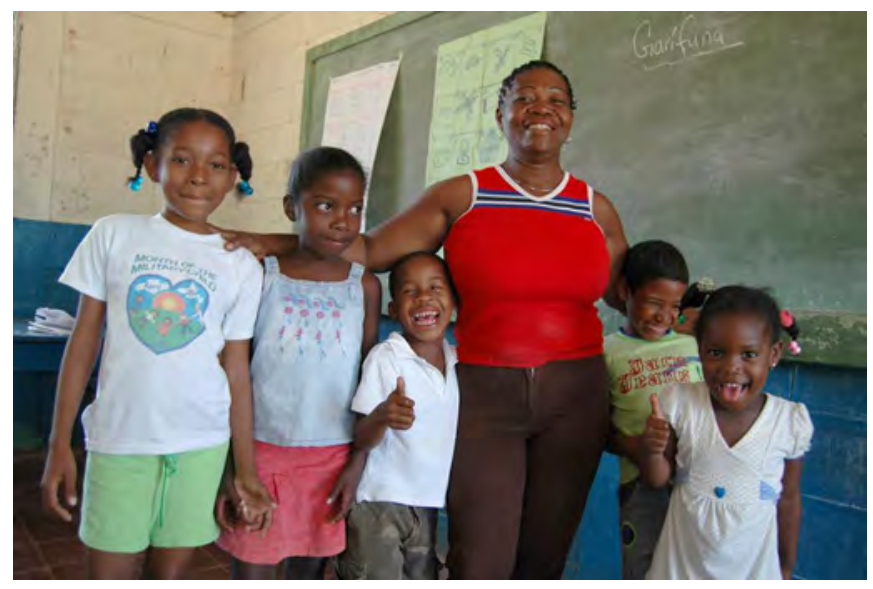

Fotografía de J. Molina. 
Imagen 15. Vela para pesca artesanal

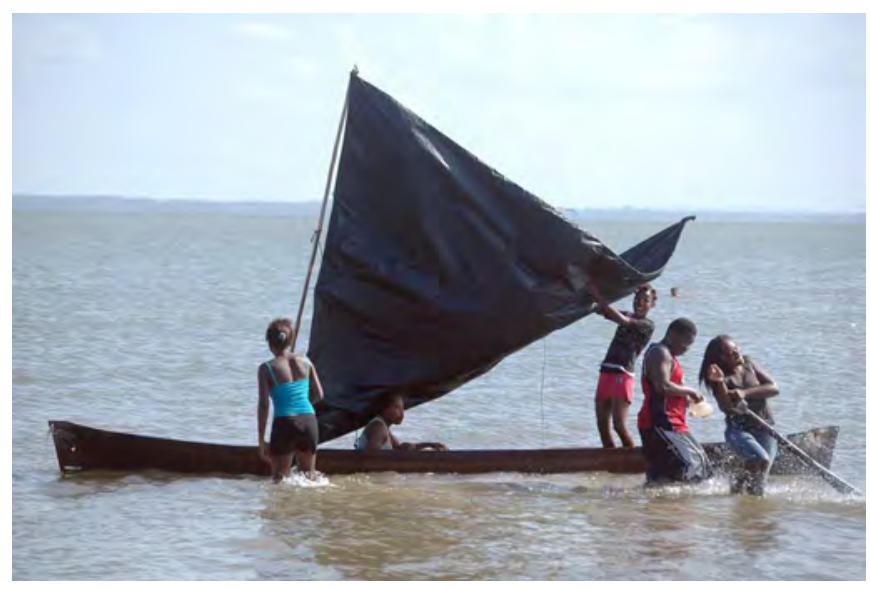

Fotografía de J. Molina.

Imagen 16. Preparación de camarones

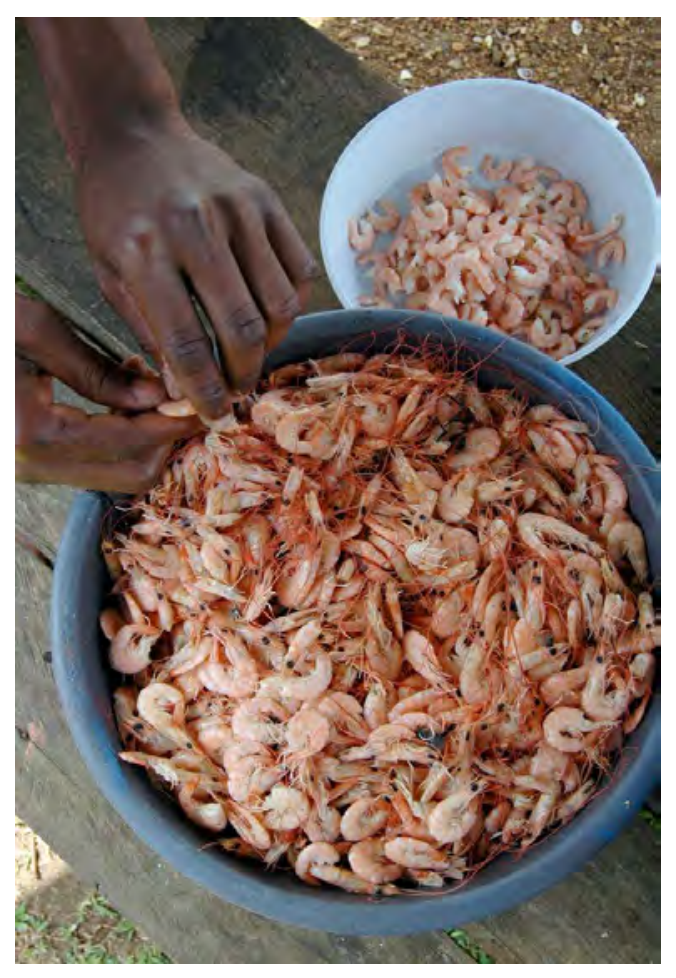

Fotografía de J. Molina. 


\section{Imagen 17. El descanso}

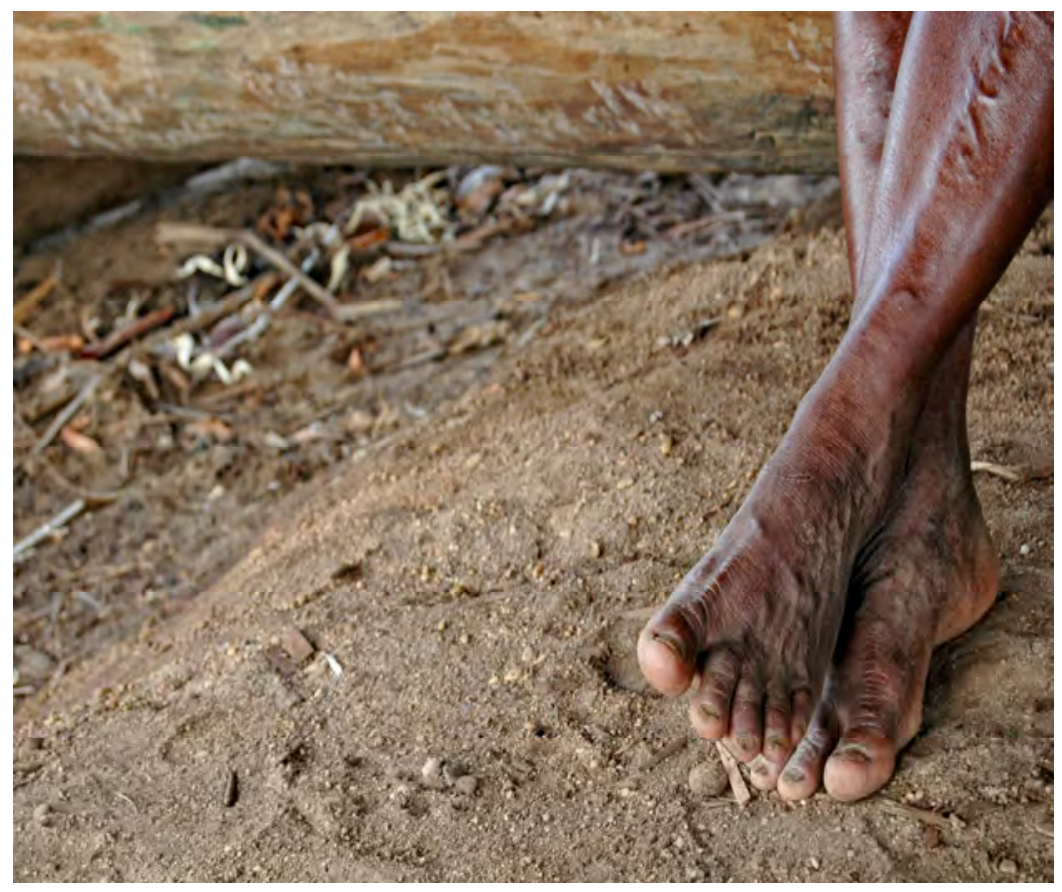

Fotografía de J. Molina.

Fecha de recepción: 14 de noviembre de 2008.

Fecha de aceptación: 1 de agosto de 2009. 